\title{
Predicting Tendency for Suicide Based on Risk Factors and Ontological Identity Using Artificial Neural Network
}

\author{
Hojjat A. Farahani \\ Tehran University, \\ Tehran, Iran
}

\author{
Zeynab Kazemi, \\ Somayeh \\ Aghamohamadi \\ University of Isfahan, \\ Isfahan, Iran
}

\author{
Mojtaba Ansari \\ Tehran Science and \\ Research University, \\ Tehran, Iran
}

\author{
Mehdi Aghamohamadi \\ Payame Noor University, \\ Najafabad, Iran
}

\begin{abstract}
The purpose of this research was to offer a model for predicting the rate of tendency for suicide in individuals and also the importance number of the risk factors involved in suicide, using artificial neural network. Furthermore, the relationship between ontological identity and suicide was examined. Six hundred and ninety-eight participants (557 females and 141 males) in this research in Isfahan were selected by convenience sampling method. The age range of the sample individuals was 19 to 41 years $(M=22.2)$. In this research, an artificial neural network was offered to draw the relationship among 32 suicide risk factors. All the risk factors presented in former researches, besides ontological identity had a role in the network. The accuracy of classification of this network in predicting the tendency of suicide in various individuals was 90.5. Also, the importance number of the suicide risk factors was shown using neural network. Ontological identity obtained the first rank among all the risk factors. Therefore, this research confirmed the roles of all presented risk factors in former researches, besides ontological identity, in suicide and provided a hierarchy of risk factors in suicide.
\end{abstract}

Keywords: tendency for suicide, risk factors, ontological identity, artificial neural network

\section{Introduction}

Suicide is a phenomenon existing as long as human kinds have existed. Inconsistent with life principle, suicide has been condemned in all societies and cultures. Suicide is an action aimed at deliberate terminating of one's life and is committed consciously. A suicidal individual sends out some signals springing from suffering and stress (B. Sadock \& V. Sadock, 2005). Suicide is a major problem in health and hygiene of society. About $9 \%$ of all deaths are due to suicide and nearly 1,000 suicides are committed each day all over the world (Levin, 2009). The rate of suicide has increased during the last 50 years. One million people die due to suicide each year in the world (Grzywa, A. Kucmin, \& T. Kucmin, 2009). In spite of the facts, suicide is a complex and multi-dimensional phenomenon influenced by individual, social and cognitive factors. During last few decades, many studies have been done on suicide and the results have shown that suicide is correlated with

Hojjat A. Farahani, Ph.D., Instructor of Faculty of Educational Sciences and Psychology, Tehran University.

Zeynab Kazemi, Faculty of Educational Sciences and Psychology, University of Isfahan.

Somayeh Aghamohamadi, Faculty of Educational Sciences and Psychology, University of Isfahan.

Mojtaba Ansari, Clinical Psychology Department, Tehran Science and Research University.

Mehdi Aghamohamadi, Computer Engineering and IT Department, Payame Noor University. 
multi-factorial risk factors including biological, psychological, social and family risk factors (Liu \& Tein, 2005). Generally, there are two major reasons involved in suicide: (1) medical factors including physical illnesses, mental disorder and substance dependency; and (2) social factors including celibacy, unemployment, divorce, losing close relatives, parents' divorce, poverty, financial problem and rate of religiosity, etc. (Gelder, Mayou, \& Geddes, 1999).

The first category shows medical factors related to suicide. Suicide is related to physical illness (Beautrais, Joyce, \& Mulder, 1997; Heikkinen, Isometsa, Aro, Sarna, \& Lonnqvist, 1995). According to Roy's (1999) research, $75 \%$ of suicide victims have had physical illness. In this study, almost $95 \%$ of patients who had committed suicide had some sorts of special mental disorder including depressive disorders (80\%), schizophrenia (10\%) and dementia (5\%). Therefore, committing suicide is highly related to depression (Fergusson \& Woodward, 2002; Lee, Wong, Chow, \& McBrid-Chang, 2006). Also, based on research literature, suicide is related to anxiety (Yamada, 2007; Lee et al., 2006; Norton, Temple, \& Pettit, 2008) and substance abuse disorders (Howard, Wang, \& Yan, 2008; Wild, Flisherc, \& Lombard, 2004; Liu \& Tein, 2005).

The second category constitutes social factors related to suicide. The most important factors related to suicide which have been mentioned in the former researches include: celibacy (Khorshidi, Yasemi, Asasi, \& Zamani, 2004), divorce (Wyder, Ward, \& De Leo, 2009), illegitimate sexual intercourse (Howard et al., 2008; Hallfors, Waller, Ford, Halpern, Brodish, \& Iritani, 2004), unemployment and financial poverty (Beautrais, 2003; Nock, Borges, Bromet, Cha, Kessler, \& Lee, 2008), rate of religiously (Shakery, Parvizi Fard, Sadeghy, \& Moradi, 2004; Neeleman \& Lewis, 1999) and urban life vs. rural life (Shams Alizadeh, Afkham Zadeh, Mohsen Poor, \& Salehian, 2011; Salarilak, Entezarmahdi, \& Abbasi, 2006; Ghamari, Zahed, \& Navid, 2010). Furthermore, life stressors predicting suicide include close relatives' death (Larosa, Consoli, Hubert-Vadenay, \& Leclesiau, 2005; Kushan, Shegerf, Rabbanizadeh, Heidary, Tofighian, \& Maskani, 2007), divorce and parental arguments (Larosa et al., 2005), child abuse history and violence in family (Langhinrichsen-Rohling, Arata, Bowers, O’ Brien, \& Morgan, 2004; Nock \& Kessler, 2006; Swahn \& Bossarte, 2007), love relationship failure (Khalkhali, Rahbar, Fardmas’ood, \& Jamadi, 2001), educational failure (Kushan et al., 2007; Lee et al., 2006). Also, committing suicide in close relatives and friends (Nock \& Kessler, 2006; Swahn \& Bossarte, 2007) and one's prior attempted suicide (Safa, Mahmoodi, Soltani Far, Saki, \& Farhadi, 2006) increase the risk of suicide. Age and sex are considered effective factors in predicting suicide as well (Sadock, 2009). Studies show that most of the people committing suicide are aged between 20 and 24 years with an average of 25 years of age (Bradley, Gaynes, Carol, Ford, Paul, Jonathan, \& Kathleen, 2004; Nock et al., 2008; Lubell, Kegler, Crosby, \& Karch, 2007). Generally, the statistics show that suicide is the 11th cause of death in whole population and third cause of death in the population aged between 15 to 24 years (April, Tracy, Nadia, Sarah, Ted, \& Thomas, 2008). Researches show that femininity is directly related to suicide (Troister, Links, \& Cutcliffe, 2008), so that in some studies in Iran, the rate of committing suicide in women is twice as much as men (Zojaji, Yasami, \& Layeghi, 2004; Zare, Nazer, \& Sayyadi, 2010). Former researches have also shown that having a purpose in life and a reason for living is related to suicide thoughts, as a cognitive factor (Range \& Penton, 1994; Ulmer, Range, \& Smith, 1991; Frankl, 1971). Awareness from one’s position in the cosmos brings about a profound sense of unity and relatedness to universe. This, as an anchor, can cause mental and physical health, life satisfaction and blissfulness (Eckstein \& Kern, 2002). Ontological identity represents one's belief in origin of life, philosophy of being and his end of life, and has a close relationship with purposefulness and meaningfulness of life (Farahani, Rahiminezhad, Aghamohamadi, \& Kazemi, 2011). In this research, the 
relationship of this concept, i.e., ontological identity with suicide will be examined for the first time.

As mentioned above, a lot of research has been done in psychology and social sciences examining suicide all of which were seeking suicide-related risk factors somehow. A necessity for predicting the tendency for suicide is recognized, because suicide is an abnormal phenomenon in human kind's behaviors. Regarding the multiplicity of risk factors involving in predicting suicide, traditionally statistical approaches such as regression cannot be suitable for such purpose, because their assumption is just based on the linear relationship (Moore \& Williams, 2002), but the neural network model, as opposed to traditional approaches for prediction, avoids simplifying relationship by combining predicting variables (Lucek, Hanke, Reich, Solla, \& Ott, 1998). Therefore, in this research, all the mentioned risk factors in the previous researches in addition to the new variable, i.e., ontological identity in predicting the tendency for suicide will be examined by the neural network model and thus, a clear picture of predicting factors of the tendency for suicide will be depicted. Furthermore, in the previous researches, although the importance of the suicide-related variables has been examined, the rate of significance of these variables in the tendency for suicide has been examined less. So, in this research, the rate of the significance of the risk factors in predicting the tendency for suicide will be analyzed. Regarding the fact that, in this research, the new concept of ontological identity as a cognitive factor in predicting the tendency for suicide has been examined and it seems that this variable supports other cognitive factors, such as purpose in life and meaningfulness of life, then it is expected that this variable will gain a high rank in predicting the tendency for suicide. Therefore, the purpose of current research was: (1) constructing a neural network for predicting the rate of tendency for suicide based on risk factors and ontological identity in students; and (2) determining the importance number of factors in causing the tendency for suicide in students.

\section{Method}

\section{Participants}

Participants in this research were 800 university students who were selected by convenience sampling method in Isfahan. After skipping problematic questionnaires, the sample was limited to 698 people (557 females and 141 males). The age range of the sample was 19 to 41 years with the mean age of 22.2 years and a standard deviation of 3.34 .

\section{Instruments}

According to biological, psychological, social and family risk factors involved in suicide which has been mentioned in the introduction in detail, some questionnaires and scales were selected in order to measure all these factors. These questionnaires and scales are as follows.

Demographic questionnaire. This questionnaire contains questions about gender, age, marital status, housing status, education, educational achievement, financial status of the family, the number of family members, order of birth, occupation, death of close relatives, one's appearance (face and body), allergic history, history of taking psychiatric drugs, history of using narcotics or psychedelic drugs, history of implication in the law, history of a family member's or close friends' or one's committing suicide, history of family violence, history of love failures, close relationship with the opposite sex, being a child of divorced parents, the rate of participating in religious ceremonies and the rate of recreational activities.

BSSI (Beck suicide scale ideation). BSSI is a self-report scale which has developed in order to reveal and measure the intensity of attitudes and planning for committing suicide. This scale measures the items, such as 
death wish, tendency for suicide, duration and frequency of suicide thoughts, the rate of self-control preventive factors and one's preparedness for committing suicide. This scale contains 19 items within four-degree Likert scale ( 0 = "None”, 3 = "Much”). Different studies have gained a validity of 0.87 to 0.97 for this scale using Cronbach's Alpha method and a validity of 0.54 using test-retest (Beck \& Steer, 1991). In this research, a Persian form of this scale has been used which has been validated by Anisi, Fathi Ashtiani, Salimi, and Ahmadi (2005). The validity of Persian form of this scale was gained 0.95 using Cronbach's Alpha and 0.88 using test-retest method.

Brief form of DASS-21 (depression anxiety stress scale). P. F. Lovibond and S. H. Lovibond (1995) developed DASS in 1995 and reported three mental factors: depression, anxiety and stress using factor analysis. The items measure depression, anxiety and stress in the last week. DASS contains two forms: original form which contains 42 items and brief form which contains 21 items (seven items for each factor) within a four-degree Likert scale ("totally like me”, "not at all like me”). The brief form of DASS was studied by Henry and Crawford (2005). These researchers have pointed to three factors of depression, anxiety and stress which have a reliability coefficient of $0.88,0.82$ and 0.90 for these factors, respectively. Persian form of DASS-21 was validated by Samani and Jokar (2007). These researchers have reported that Persian form of DASS-21 also contains three factors of depression, anxiety and stress and Cronbach's Alpha for these factors are 0.87, 0.85 and 0.75 , respectively.

OIS (ontological identity scale). This scale was developed by Farahani et al. (2011), which includes 27 items within a five-degree Likert scale ( 1 = "Strongly disagree", 5 = "Strongly agree") according to three dimensions of "where do I come from", "where I am" and "where I go to" having been developed on an ontological viewpoint (items 1 to 9 for the dimension of "where I come from"; items 10 to 18 for the dimension of "where I am" and items 19 to 27 for the dimension of "where I go to"). Sample items are: "My coming to the world is not accidental and there is logic behind it" (where I come from); "Despite all the misery and difficulties, human beings can attain great purposes" (where I am); and "I like there to be a world after death but I'm not sure about it" (where I go to). The reliability of the ontological identity questionnaire was tested through both Cronbach's Alpha and test-retest methods and the obtained coefficients were 0.81 and 0.68 respectively. Also, the validity of this questionnaire was tested through concurrent validity and exploratory factor analysis. The concurrent validity was also tested through purpose in life scale and the correlation coefficient was significant $(0.42)$ between the ontological identity and purpose in life questionnaires $(P=$ 0.001). The exploratory principal component analysis with Varimax rotation revealed that this questionnaire has three factors which determine 43.32 of the total variance.

\section{Statistical Method}

Artificial neural network. Artificial neural network is a parallel distributive and voluminous processor which consists of simple processing units. This network is capable of learning from presented empirical knowledge in its inter-related units and can make use of the obtained learning (Kantardezic, 2002). Artificial neural network is a simplified model of human brain. In this model, neurons are the smallest constructive unite of artificial neural network. Each network consists of an input layer, an output layer and one or more middle (hidden) layers. Neurons of each layer are connected to next neurons by weights (Sabzevari, Mohammad Poor, \& Zommorodian, 2004). Through training process of the network, these weights and constant amounts, technically called bias, are added and they change continuously so that the error reaches its minimum level or 
put simply, and root-mean-square error becomes minimum. For transferring outputs of each layer to the next layers, activation functions are used (B. D. Ripley \& R. M. Ripley, 2006). There are different functions, the most famous of which include linear functions, sigmoid and threshold functions.

\section{Results}

\section{Descriptive Result}

The sample for this research included 698 students (557 females and 141 males), from whom, 545 students (78.1\%) were in low-risk tendency for suicide group and 153 students (21.9\%) were in high-risk tendency for suicide group, based on determined cutoff point. The mean age of the low-risk group was 22.06 years and the high-risk group was 22.31 years. The mean score of OIS for the low-risk group was 99.38 and that for the high-risk group was 92.72 . Also, the mean scores of stress, anxiety and depression for the low-risk group were 4.85, 4 and 5.14, and for the high-risk group were 7.29, 6.49 and 7.29 respectively.

\section{Network Specifications}

In this research, MLP (multilayer perception) artificial neural network with back propagation algorithm was used. For determining the best activation function with various functions, the network was performed and optimal function was determined based on the minimum root-mean-square error. The function used in this model for the data of this research was hyperbolic tangent function. Seventy-two point four percent of subjects were used for training sample and $27.6 \%$ were used for testing sample. For evaluating this model, RMSE (root mean square of error) and under curve, surface ROC (receiver operating characteristic) were used. The specifications of MLP artificial neural network have been presented in Table 1.

Table 1

Specifications of MLP Artificial Neural Networks Used in This Research

\begin{tabular}{|l|l|}
\hline \multicolumn{1}{|c|}{ Specifications of MLP neural network } \\
\hline Number of neurons in the input layer & 117 \\
\hline Number of hidden layers & 1 \\
\hline Number of neurons in the hidden layer & 3 \\
\hline Number of neurons in the output layer & 2 \\
\hline Type of network function & Hyperbolic tangent \\
\hline Type of network training & Back propagation \\
\hline Mean square error & 0.03 \\
\hline Number of training sample & 385 \\
\hline Number of testing sample & 147 \\
\hline Number of excluded sample & 166 \\
\hline Number of repetition & 1,000 \\
\hline
\end{tabular}

\section{Network Validity}

Table 2 shows the results accuracy, sensitivity and specificity in two models of MLP.

Table 2

The Results Related to Accuracy, Sensitivity and Specificity in MLP

\begin{tabular}{llll}
\hline Model & Accuracy & Sensitivity & Specificity \\
\hline MLP artificial neural network model & 90.5 & 0.94 & 0.85 \\
\hline
\end{tabular}


Under curve area ROC in artificial neural network for two low-risk and exposed-to-risk groups was obtained 0.938 that shows accuracy and significance of the classification. Figure 1 shows sensitivity and specificity of MLP artificial neural network. As it is seen in Figure 1, diagnostic sensitivity and specificity of MLP artificial neural network are 0.94 and 0.85 respectively, which shows that this model acts with a completely equal precision in diagnosing the individuals exposed to the suicide risk and individuals with low-risk.

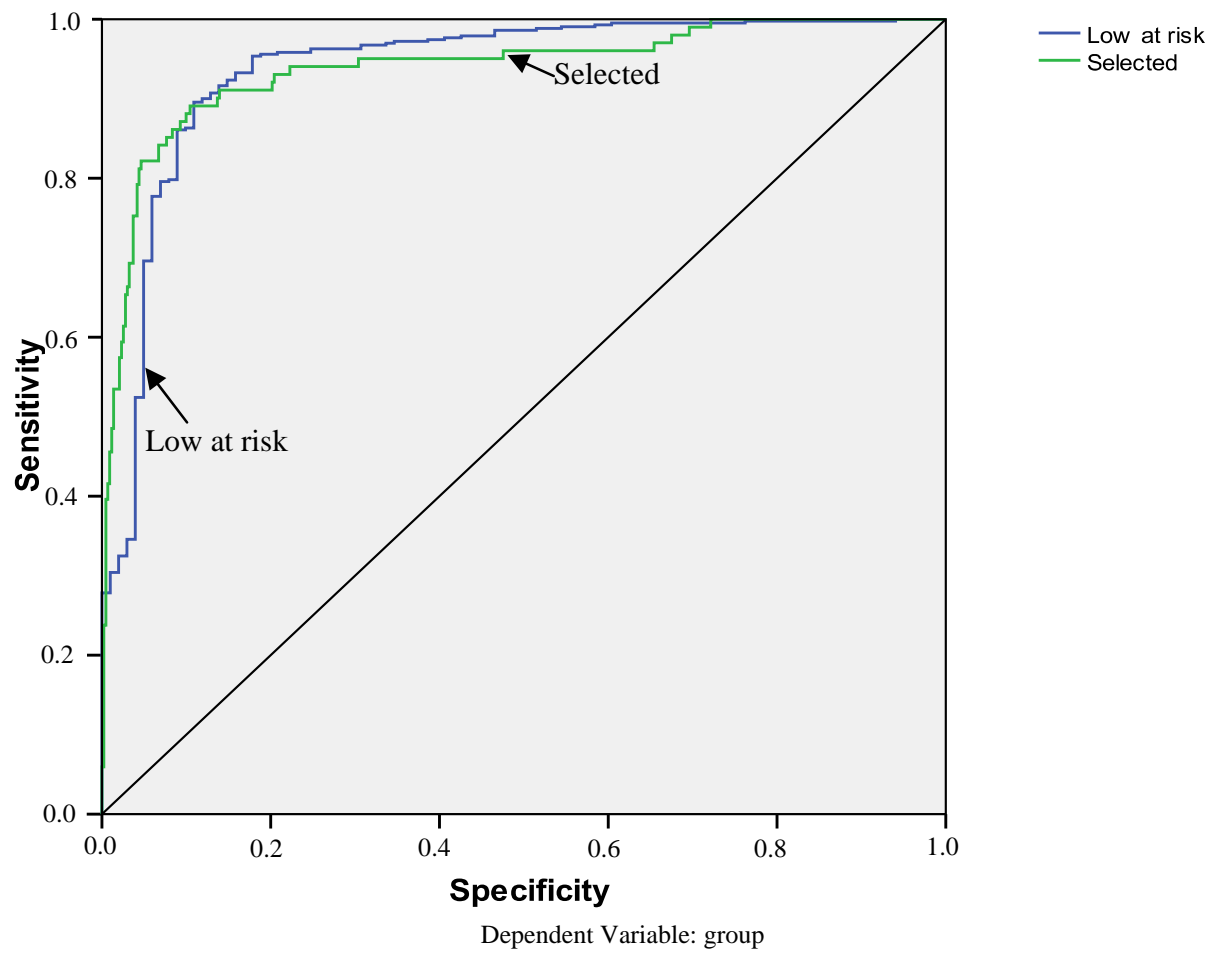

Figure 1. Sensitivity and specificity in MLP model.

Table 3

The Importance Number of Existing Variables (Factors) in MLP Neural Network

\begin{tabular}{|c|c|c|c|c|c|}
\hline Variable & $\begin{array}{l}\begin{array}{l}\text { Normalized } \\
\text { importance } \\
\text { (percentage \%) }\end{array} \\
\end{array}$ & Rank & Variable & $\begin{array}{l}\text { Normalized } \\
\text { Importance } \\
\text { (percentage \%) }\end{array}$ & Rank \\
\hline Ontological identity & 100 & 1 & Birth order & 14.4 & 15 \\
\hline Stress & 53 & 2 & Rate of religiosity & 14.3 & 16 \\
\hline Educational status & 46.3 & 3 & History of friends’ suicide & 13.3 & 17 \\
\hline History of committing suicide & 31 & 4 & Relationship with the opposite sex & 12.2 & 18 \\
\hline Family violence & 30.5 & 5 & Death of a close relative & 12.1 & 19 \\
\hline Anxiety & 20.9 & 6 & History of implication in the law & 11.8 & 20 \\
\hline Celibacy & 18.3 & 7 & Recreational activities & 11.7 & 21 \\
\hline Number of family members & 18 & 8 & Child of divorced parents & 11.6 & 22 \\
\hline Financial poverty & 17.6 & 9 & Urban life & 10.6 & 23 \\
\hline Educational average & 17 & 10 & History of suicide in family members & 10 & 24 \\
\hline Satisfaction from one's appearance & 16.5 & 11 & Body fitness & 8.6 & 25 \\
\hline Unemployment & 16.4 & 12 & Gender & 8.4 & 26 \\
\hline Participating in religious ceremonies & 16.4 & 12 & History of psychedelic drugs use & 6.5 & 27 \\
\hline Depression & 15.3 & 13 & Allergy & 5.5 & 28 \\
\hline Housing status & 15.3 & 13 & History of using narcotics & 5.2 & 29 \\
\hline History of educational failure & 14.5 & 14 & Love failure & 2.9 & 30 \\
\hline
\end{tabular}




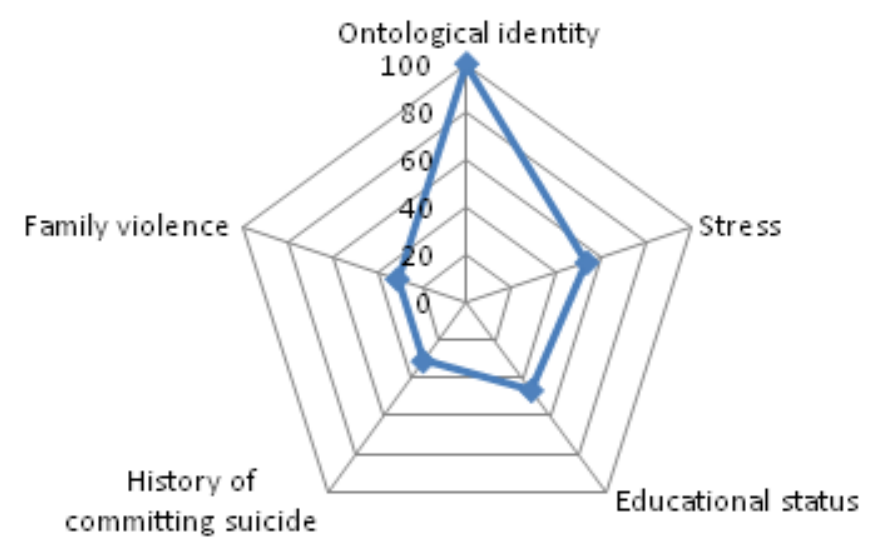

Figure 2. Spider chart for the main heading of variables.

Table 3 shows importance number of existing variables in MLP neural network model.

As it is seen in Figure 2, all variables have roles and their importance percentages are specified. Among these variables, variables of ontological identity, stress, educational status, history of committing suicide, family violence, anxiety and celibacy respectively have the most impacts on artificial neural network in classifying the individuals with high and low risk of suicide tendency and the rest of variables have also been effective in predicting the tendency for suicide.

\section{Conclusions}

Researchers in different researches have introduced various factors as important risk factors in predicting suicide tendency using classical statistical models. The major merit of artificial neural networks used in this research is that it does not need the presupposition of being linear and we can model with it predictive models having different features and indeterminate functions (Koochakzadeh \& Bahmani, 2005). The other merit of the artificial neural network is that it can be trained for performing a special function via moderating the amounts of weights among model factors. Artificial neural networks consist of factors that act parallel, and therefore, the pace of classifying is very high (Hagan \& Dennutu, 2003). Also, artificial neural networks prevent over-simplification of the relationships (Figueroa \& Cousseau, 2008). These merits make the use of this method preferable to classical statistical methods for prediction such as logistic regression. The first purpose of this research was that artificial neural network makes possible a reliable prediction for individuals exposed to high risk or low risk for suicide. Therefore, by using artificial neural network, various risk factors expressed in different researches were used to predict the rate of tendency of committing suicide. The results showed that the artificial neural network had an accuracy of 90.5 in classifying and predicting the high or low risk of suicide in different individuals in the testing phase. So, if the individual's characteristics are given to the network according to mentioned factors, an accurate prediction of the risk of the tendency for suicide will be provided. The later purpose of this research was to examine the importance number of the risk factors of tendency for suicide in Iranian student sample using an artificial neural network. In the other words, in the second part of the research, a hierarchy of the effective variables in the tendency for suicide in Iranian student was provided, using an artificial neural network (see Table 3).

The results of the previous researches show that the highest rate of committing suicide in Iran was found many individuals aged between 17 and 24 and with the increasing of age, the prevalence of committing suicide 
decreases (Khazayee \& Parvizi Fard, 2002; Khalkhali et al., 2001; Ghamari et al., 2010). It is worth mentioning that Iran has a youthful population and the youthfulness of the population dousing in one region can create an age bias. Therefore, it seems that the significance of the suicide-related risk factors in Iran is related to psychological state of this age group. Adolescents, due to characteristics, such as emotion lability, criticism in tolerance, frustration intolerance, romantic states and lovesickness, occupational and educational worries, independency need, the need for religion and life philosophy, the need for a sense of identity and knowing oneself and the need for having a goal in life (Khodayari Fard, 1996), show more fragility when encountering dire situations of life and feel that they have no way back. In this research, ontological identity was of the first importance. Ontological identity is an interdisciplinary construct that has bridged between self-psychology and philosophy. This construct has borrowed the concept of identity from self-psychology and the concept of ontology from philosophy. Generally, ontology answers to the questions about philosophy of life, such as "What position do I have in the universe as a human-being?”, "Where do I come from?”, "Why do I have come?” and "Where will I go to?” (Farahani et al., 2011). Identity is an image a person has from himself/herself and results from answering the question: "Who am I?” (Erikson, 1968). Identity includes different kinds of identities, such as individual, social, racial and national identity. Ontological identity shows a belief one that has about the origin of life, the philosophy of being and the end of one's life (after life) and has a close relationship with life purposefulness and meaningfulness (Farahani et al., 2011). The former researches have also discovered the relationship between purposes in life and suicide (Ulmer et al., 1991), and have discovered the relationship between suicide and having reason for living (Linehan et al., 1983; Range \& Penton, 1994) as well. Frankl (1971) suggested that asking about a person's reasons for not choosing suicide was a useful method of inquiring into potential sources of meaning or purpose in his/her life. Therefore, it seems that the people who do not have a cognitive justification for coming to this world and living there will experience purposelessness and meaninglessness and are exposed more to suicide. Those, who assume their existences in this world as an accidental phenomenon and consider it futile and meaningless to live there, are more likely to commit suicide. In the other words, ontological identity can be in line with the adolescent's authentic need for knowing the philosophy of life and knowing oneself more so that he/her can attach a goal and meaning to his life. The next factor which was ranked second in this research was the rate of stress. Individuals committing suicide have been exposed to more stressors in life (Katherine \& Patricce, 2000). One of the reasons can be the fact that the individuals have not learned the effective coping skills in the life stressors, or they have evaluated the life problems direr and more intense due to the special personality characteristics and stressful experiences (Shakery et al., 2004). Also, it has been noted in various researches that individual that had committed suicide, experienced a lot of psycho-social problems a year before committing suicide. In a research done in Iran, the major problems before committing suicide were as follows respectively: problem with the partner, the family, financial, occupational educational and legal problems (Nojomi, Bolhari, Malakouti, Hakim Shooshtari, Asgharzadeh Amin, \& Posht Mashhadi, 2005). Also, other researchers have come up with other problems, such as love-relationship failures, a constant discord between parents and their divorce, emerging server prolonged physical illnesses (Ganji, 2000), the death of a close relative/friend, relationship with opposite sex, urban life and housing problems, a great number of family members and mental illnesses which have been mentioned in the introduction. The role of these stressors is different in committing suicide. Regarding the fact that our research sample was completely chosen from university students, the importance number of major stressors before committing suicide was obtained in Iranian university students (see Table 3). It seems that there is an 
age-related pattern in life events before committing suicide. Age distribution of the life events showed that physical illness and the death of close relatives/friends are seen in upper ages more, and financial and interpersonal relationship problems are seen in lower ages more. For example, in the late adolescence and early adulthood, there is an increased tendency for establishing a constant and intimate relationship with an opposite-sex partner and, in the old age, there is an increased re-dependency on others and is accompanied with disability and illness (Heikkinen et al., 1995; Khalkhali et al., 2001). Also, the importance number of stressors is influenced by sex differences. The women experience stressors, such as marital discords, struggle with the family, emotional problems and educational failure more than other psycho-social stressors, while men experience occupational and financial problems more than other psycho-social factors before committing suicide (Shakery et al., 2004). In a research devised by WHO (World Health Organization) for examining individuals committing suicide in Karaj city in 2003, it was shown that $28 \%$ of those individuals had a prior record of attempted suicide and $15.4 \%$ had a prior record of committing suicide in the relatives (Nojomi et al., 2005). In this research as well, a record of attempted suicide ranked fourth and a record of committing suicide in friends and the family ranked 17th and 24th respectively, which shows the greater importance of a record of committing suicide as a risk factor for predicting the tendency for suicide. In a research done in Iran, it has been shown that $32 \%$ of suicidal individuals' relatives, thought the mental illness is the cause of their suicide but only $4 \%$ of the individuals had a record of going to a psychiatrist (Yasemi, Sabahi, Mirhashemi, Seifi, Azar Keivan, \& Tahei, 2002). In this research as well, anxiety and depression were ranked 6th and 13th respectively but a record of using psychiatric drugs gained a rank of 27. In most Iranian and foreign studies, the women commit suicide more (Nojomi et al., 2005; Molavi, Abbasi, \& Mohammadnia, 2006; Arefi, 2002; Dilsaver, Chen, Swann, Shoaib, \& Krajewski, 1994), while in this research the sex variable gained a rank of 26 which shows in the Iranian students, the sex variable does not have a great predictability. An explanation for this is the high education of the women in our sample, since in the various Iranian researches, it has been noted that the rate of suicide decreases as the level of the education increases (Molavi et al., 2006; Safa et al., 2006; Khalkhali et al., 2001) and in this research also the education status factor was ranked third. Also, the rate of participating in religious ceremonies was ranked higher (12th) than the rate of religiosity (16th) in predicting suicide. At the end, it is necessary to note that other variables, such as personality features, genetic factors and other mental illnesses, e.g., OCD (obsessive compulsive disorder) plays a role in the rate of the suicide tendency in individuals, but in this research they were not dealt with. Also, the findings of this research pertain to the population of Iranian university students and, thus, in generalizing, those to other populations should be treated with caution.

\section{References}

Anisi, J., Fathi Ashtiani, A., Salimi, H., \& Ahmadi, K. H. (2005). In evaluation of validity and reliability of Beck suicide scale ideation (BSSI) in soldiers. Military Medicine, 7(1), 33-37. (in Persian)

April, R. S., Tracy, K. W., Nadia, E. T., Sarah, L. K., Ted, W. B., \& Thomas, E. J. (2008). Revisiting impulsivity in suicide: Implications for civil liability of third parties. Journal Behavior Sciences and the Law, 26, 779-797.

Arefi, M. (2002). Examining the suicide rate in Wastern Azarbaijan County between years 1998, 1999 and accessing some of variables affecting. Journal of Psychology and Educational Sciences, 33(1), 141-162. (in Persian)

Beautrais, A. L. (2003). Suicide and serious suicide attempts in youth: A multiple-group comparison study. Journal of Psychiatry, 160, 1093-1999.

Beautrais, A. L., Joyce, P. R., \& Mulder, R. T. (1997). Precipitating factors and life events in serious suicide attempts youths aged 13 through 24 years. Journal of the American Academy of Child and Adolescent Psychiatry, 36(11), 1543-1551. 
Beck, A. T., \& Steer. R. A. (1991). Manual for the Beck scale for suicide ideation. San Antonia, T. X.: Psychological Corporation.

Bradley, N., Gaynes, S. L., Carol, A., Ford, D., Paul, S. F., Jonathan, K., \& Kathleen, N. L. (2004). Screening for suicide risk in adults: A summary of the evidence for the US preventive services task force. Annals of Internal Medicine, 140, 822-835.

Dilsaver, S. C., Chen, Y. W., Swann, A. C., Shoaib, A. M., \& Krajewski, K. J. (1994). Suicidality in patients with pare and depressive mania. The American Journal of Psychiatry, 151, 1312-1315.

Eckstein, D., \& Kren, R. (2002). Life style assessments in the intervention, lifestyle skills. Lowa: Kendall/Hunt, 58(1), 64-78.

Erikson, E. H. (1968). Identity, youth and crisis. New York: Noton.

Farahani, H. A., Rahiminezhad, A., Aghamohamadi, S., \& Kazemi, Z. (2011). Development and validation of a scale on ontological identity (OIS). Journal of Procedia Social and Behavioral Sciences, 15, 3268-3271.

Fergusson, D. M., \& Woodward, L. J. (2002). Mental health, educational and social role outcomes of adolescents with depression. Archives of General Psychiatry, 59, 225-231.

Figueroa, J. L., \& Cousseau, J. E. (2008). Dynamical functional artificial neural network: Use of efficient piecewise linear functions. Latin American Applied Research, 38, 127-193.

Frankl, V. E. (1971). The doctor and the soul: From psychotherapy to logotherapy. New York: Bantam.

Ganji, H. (2000). Mental health (pp. 149-156). Tehran: Arasbaran Publication. (in Persian)

Gelder, M., Mayou, R., \& Geddes, J. (1999). Oxford core text psychiatry (2nd ed.). Oxford: Oxford University Press.

Ghamari, H., Zahed, F., \& Navid, S. (2010). Suggesting an evaluation model for filling out and completing the legal files of success suicides. Journal of Forensic Medicine, 16(1), 33-39. (in Persian)

Grzywa, A., Kucmin, A., \& Kucmin, T. (2009). Suicide problems-epidemiology, factors, motives and prevention. Pol Merkur Lekarski, 27, 432-436.

Hagan, M., \& Dennutu, H. (2003). Neutral network. Design Beston: PWS.

Hallfors, D., Waller, M., Ford, C., Halpern, C., Brodish, P., \& Iritani, B. (2004). Adolescent depression and suicide risk: Association with sex and drug behavior. American Journal of Preventive Medicine, 27, 224-231.

Henry, J. D., \& Crawford, J. R. (2005). The short form of the depression anxiety stress scale (DASS-21): Construct validity and normative data in a large non-clinical sample. British Journal of Clinical Psychology, 44, 337-239.

Heikkinen, M. E., Isometsa, E. T., Aro, H. M., Sarna, S. J., \& Lonnqvist, J. K. (1995). Age-related variation in recent life events preceding suicide. Journal of Nervous and Mental Disease, 183(5), 325-231.

Howard, D. F., Wang, M. Q., \& Yan, F. (2008). Psychosocial factors associated with reports of physical dating violence victimization among US. Adolescent Males Adolescence, 43(171), 449-460.

Kantardzic, M. (2002). Data mining (A. Alikhanzadeh trans., 2006). Tehran: Publications of Computer Sciences. (in Persian)

Katherine, M., \& Patricce, A. (2000). Psychiatric mental health nursing. New York: Mosby, Inc..

Khalkhali, M. R., Rahbar, S., Fard Masoud, R., \& Jamadi, A. (2001).Examining life events in suicidal individuals. Journal of Medical Faculty of Gilan Medical University, 10 (39 \& 40), 96-106. (in Persian)

Khazayee, H. A., \& Parvizi Fard, A. A. (2001). Examining demographic features and evaluating the mental status of the individuals committing suicide. Scientific and Research Journal of Kermanshah Medical University, 7(3), 40-45. (in Persian)

Khodayari Fard, M. (1996). Adolescents' and youths' problems (4th ed., pp. 40-45) Tehran: Koleini publication. (in Persian)

Khorshidi, A., Yasemi, M. T., Asasi, N., \& Zamani, G. H. (2004). Determining the burden caused by suicidal behavior in Ilam. Journals of Payesh, 3(4), 57-64. (in Persian)

Koochakzadeh, M., \& Bahmani, A. A. (2005). Evaluation of artificial neural networks performance in reducing the parameters needed for estimating source steaming and perspiration. Journal of Medical Science, 11, 87-95. (in Persian)

Kushan, M., Shegerf, M. R., Rabbanizadeh, A., Heidary, A., Tofighian, T., \& Maskani, K. (2007). Examining the prevalence of suicide factors in hospitalized individuals committing suicide in Vasei hospital in Sabzevar. Journal of Therapeutic-Hygienic Services and Medical University, 15(2), 123-138. (in Persian)

Langhinrichsen-Rohling, J., Arata, C., Bowers, D., O’Brien, N., \& Morgan, A. (2004). Suicidal behavior, negative effect, gender, and self-reported delinquency in college students. Suicide and Life-Threatening Behavior, 34, 255-266.

Larosa, E., Consoli, S. M., Hubert-vadenay, T., \& Leclesiau. (2005). Factors associated with suicidal risk among consulting young people in a preventive health center. Encephala, 31(3), 289-299.

Lee, M. T., Wong, B. P., Chow, B. W., \& McBride-Chang, C. (2006). Predictors of suicide ideation and depression in Hong Kong adolescents: Perception of academic and family climates. Suicide Life Threat Behavior, 36(1), 82-96.

Levin, A. (2009). The startling increase in the number of suicides by members of the US army in the last few years prompts a major collaborative study of risk and protective factors. Psychiatric News, 44(16), 1. 
Linehan, M. M., Goodstein, J. L., Nielsen, S. L., \& Chiles, J. A. (1983). Reasons for staying alive when you are thinking of killing yourself: The reasons for living inventory. Journal of Consulting and Clinical Psychology, 51, 276-286.

Liu, X., \& Tein, J. (2005). Life events, psychopathology, and suicidal behavior in Chinese adolescents. Affective Disorders, 86, 195-203.

Lovibond, P. F., \& Lovibond, S. H. (1995). The structure of negative emotional states: Comparison of the depression anxiety inventories. Behavior Research and Therapy, 33, 335-342.

Lubell, K. M., Kegler, S. R., Crosby, A. E., \& Karch, D. (2007). Suicide trends among youths and young adults aged 10-24 years, United States, 1990-2004. Retrieved from http://www.cdc.gov/mmwr/preview/mmwrhtml/mm5635a2.htm

Lucek, P., Hanke, J., Reich, J., Solla, S. A., \& Ott, J. (1998). Multi-locus nonparametric linkage analysis of complex trait loci with neural networks. Journal of Human Heredity, 48, 275-284.

Molavi, P., Abbasi,V., \& Mohammadnia, H. (2006). Examining risk factors of committing suicide in Ardebil. Journal of Rehabilitation, 8(1), 67-71. (in Persian)

Moore, J. H., \& Williams, S. M. (2002). New strategies for identifying gene-Gene interactions in hypertension. Journal of Annals of Medicine, 34, 88-95.

Neeleman, J., \& Lewis, G. (1999). Suicide, religion, and socioeconomic conditions: An ecological study in 26 countries, 1990. Journal of Epidemiology and Community Health, 53(4), 204-210.

Nojomi, M., Bolhari. J., Malakouti, S. K., Hakim Shooshtari, M., Asgharzadeh Amin, S., \& Posht Mashhadi, M. (2005). The study of demographic characteristics of suicide attempters attending emergency rooms of Karaj hospitals in 2003-2004. Journal of (Tehran) Medical University, 13(52), 225-234. (in Persian)

Nock, M. K., \& Kessler, R. C. (2006). Prevalence of and risk factors for suicide attempts versus suicide gestures: Analysis of the national comorbidity survey. Journal of Abnormal Psychology, 115, 616-623.

Nock, K. M., Borges, G., Bromet, E. J., Cha, B. C., Kessler, R. C., \& Lee, S. (2008). Suicide and suicidal behavior. Epidemiological Review, 30, 133-154.

Norton, P. J., Temple, S. R., \& Pettit, J. W. (2008). Suicidal ideation and anxiety disorders: Elevated risk or artifact of comorbid depression?. Journal Behavior Therapy and Experimental Psychiatry, 39, 515-525.

Range, L. M., \& Penton, S. R. (1994). Hope, hopelessness, and suicidality in college students. Psychological Reports, 75, 456-458.

Ripley, B. D., \& Reipley, R. M. (2006). Neural networks as statistical methods in survival analysis. Journal of Statistics, 409-456.

Roy, A. (1999). Psychiatric emergencies (7th ed.). Lippincott: Textbook of psychiatry.

Sabzevari, T., Mohammad Poor, R., \& Zommorodian, M. A. (2004). Estimating the parameters of the cracks of soil dams using neural networks. The First Congress of Civil Engineering, Sharif Industrial University, Ordibehesht 22-24th. (in Persian)

Sadock, B. (2009). Psychiatric emergencies in Sadock B, Sadock V, Ruiz P. Kaplan and Sadocks comprehensive textbook of psychiatry (9th ed., Vol. 2). Lippincott Williams \& Wilkins.

Sadock, B., \& Sadock, V. (2005). Kaplan and Sadocks pocket hand book of clinical psychiatry (4th ed., Vol. l). Lippincott Willams and Wilkins.

Safa, M., Mahmoodi, Gh. A., Soltani Far, M., Saki, M., \& Farhadi, A. (2006). Examining individualistic, family, psychological features and drug abuse in hospitalized and suicidal patients in Shohadaye Ashayer in 2004. Journal of Lorestan Medical University, 9(2), 31-37. (in Persian)

Salarilak, S. H., Entezarmahdi, R., Afshani, M. T., \& Abbasi, H. (2006). A survey of rate and effective factors on occurrence of suicide during one year in. Urmia Medical Journal, 2, 93-100. (in Persian)

Samani, S., \& Jokar, B. (2007). Examining validity and reliability of brief form depression, anxiety and stress scale. Journal of Social Sciences and Humanities of Shiraz University, 26(3), 65-77. (in Persian)

Shakery, J., Parvizi Fard, A. A., Sadeghy, K. H. A., \& Moradi, R. (2004). Personality characteristics, stress, coping mechanisms and religious attitudes in suicidal individuals. Retrieved from http//:www.sid.ir (in Persian)

Shams Alizadeh, N., Afkham Zadeh, A. R., Mohsen Poor, B., \& Salehian, B. (2011). Commiting suicide and its related factors in Kordestan. Journal of Medical Faculty of Kordestan Medical University, 15, 79-84. (in Persian)

Swahn, M., \& Bossarte, R. (2007). Gender, early alcohol use, and suicide ideation and attempts: Findings from the 2005 youth risk behavior survey. Journal of Adolescent Health, 41, 175-181.

Troister, T., Links, P. S., \& Cutcliffe, J. (2008). Review of predictor of suicide within 1 year of discharge from a psychiatric hospital. Current Psychiatry Reports, 10(1), 60-65.

Ulmer, A., Range, L. M., \& Smith, P. C. (1991). Purpose in life: A moderator of recovery from bereavement. Omega, 23(4), 279-289. 
Wild, L. G., Flisherc, A. J., \& Lombard, C. (2004). Suicidal ideation and attempts in adolescents: Associations with depression and six domains of self-esteem. Journal of Adolescence, 27, 611-624.

Wyder, M., Ward, P., \& De Leo, D. (2009). Separation as a suicide risk factor. Journal Affect Disorder, 16(3), 208-213.

Yasemi, M. T., Sabahi, A., Mirhashemi, M., Seifi, S. H., Azar Keivan, P., \& Tahei, M. H. (2002). Epidemiology of suicide by forensic medicine in Karmanshah County. Thought and Behavior, 7(4), 4-12. (in Persian)

Yamada, M. (2007). Depression and suicide prevention, Nippon Rinsho, 65(9), 1675-1688.

Zare, H., Nazer, M., \& Sayyadi, A. R. (2010). Frequency of mental disorders and factors related to suicide in patients referring to emergency ward of Ali Ebne Abitaleb hospital of Rafsanjan in 2007. Journal of University of Medical Sciences Rafsanjan, 9(3), 221-232. (in Persian)

Zojaji, A., Yasami, M. T., \& Layeghi, H. (2004). A program to predict of suicide in primary health system: The official of preventing of diseases, ministry of health. Journal of Sazman Behzisti., 8, 78-93. (in Persian) 